Bull. Mater. Sci., Vol. 36, No. 6, November 2013, pp. 1067-1072. (C) Indian Academy of Sciences.

\title{
Chemical shift of Mn and Cr K-edges in X-ray absorption spectroscopy with synchrotron radiation
}

\author{
D JOSEPH ${ }^{\dagger}$, A K YADAV $¥$, S N JHA ${ }^{\ddagger}$ and D BHATTACHARYYA \\ ${ }^{\dagger}$ Nuclear Physics Division, ${ }^{\ddagger}$ Applied Spectroscopy Division, Bhabha Atomic Research Centre, \\ Mumbai 400 085, India
}

MS received 2 May 2012

\begin{abstract}
Mn and $\mathrm{Cr}$ K X-ray absorption edges were measured in various compounds containing $\mathrm{Mn}_{\text {in }} \mathrm{Mn}^{2+}$, $\mathrm{Mn}^{3+}$ and $\mathrm{Mn}^{4+}$ oxidation states and $\mathrm{Cr}$ in $\mathrm{Cr}^{3+}$ and $\mathrm{Cr}^{6+}$ oxidation states. Few compounds possess tetrahedral coordination in the 1st shell surrounding the cation while others possess octahedral coordination. Measurements have been carried out at the energy dispersive EXAFS beamline at INDUS-2 Synchrotron Radiation Source at Raja Ramanna Centre for Advanced Technology, Indore. Energy shifts of $\sim 8-16 \mathrm{eV}$ were observed for Mn K edge in the Mn-compounds while a shift of 13-20 eV was observed for $\mathrm{Cr} \mathrm{K}$ edge in $\mathrm{Cr}$-compounds compared to values in elemental $\mathrm{Mn}$ and $\mathrm{Cr}$, respectively. The different chemical shifts observed for compounds having the same oxidation state of the cation but different anions or ligands show the effect of different chemical environments surrounding the cations in determining their $\mathrm{X}$-ray absorption edges in the above compounds. The above chemical effect has been quantitatively described by determining the effective charges on $\mathrm{Mn}$ and $\mathrm{Cr}$ cations in the above compounds.
\end{abstract}

Keywords. Mn K edge; Cr K edge; EXAFS; synchrotron radiation; energy shift; oxidation state; effective charge.

\section{Introduction}

It is well known that the X-ray absorption edge of a metal atom changes from its elemental state when it takes part in the formation of a compound. Generally, the absorption edge shifts to higher energy as the core electron binding energy increases, since the metal atom transforms to a positive ion while participating in the formation of a chemical bond and this energy shift $(\Delta E)$ increases with an increase in the oxidation state or positive charge on the metal ions. Thus, as the valency or oxidation state of the metal increases, the absorption edge ideally should shift towards higher value. However, as many researchers have observed (Nigam and Gupta 1974; Kondawar and Mande 1976; Ballal and Mande 1977; Apte and Mande 1981; Chetal et al 1988; Pandey et al 1990; Hinge et al 2011; Joseph et al 2012), even at the same oxidation state, the absorption edge shifts to different extents depending on several other factors viz. nature of the ligands to the metal ion, coordination numbers, covalent character of the bond, electronegativity of the anion etc or in other words, the chemical environment of the metal ion. The change in absorption edge which could be attributed to different chemical environments of a metal ion having same oxidation state is generally known as chemical effect.

In the present study, we have investigated the chemical effect in different compounds of $\mathrm{Mn}$ viz. $\mathrm{MnCl}_{2}, \mathrm{MnCO}_{3}$, $\mathrm{MnSO}_{4} \cdot \mathrm{H}_{2} \mathrm{O}, \mathrm{Mn}_{2} \mathrm{O}_{3}, \mathrm{CaMnO}_{3}$ and $\mathrm{MnO}_{2}$, where $\mathrm{Mn}$ is

\footnotetext{
*Author for correspondence (dibyendu@barc.gov.in)
}

present in different oxidation states $\left(2^{+}, 3^{+}\right.$and $4^{+}$states $)$ and in different compounds of $\mathrm{Cr}$ viz. $\mathrm{CrCl}_{3} \cdot 6 \mathrm{H}_{2} \mathrm{O}, \mathrm{Cr}_{2} \mathrm{O}_{3}$, $\mathrm{Cr}\left(\mathrm{SO}_{4}\right)_{3}, \mathrm{Cr}_{2}\left(\mathrm{NO}_{3}\right)_{3} \cdot 3 \mathrm{H}_{2} \mathrm{O}, \mathrm{K}_{2} \mathrm{Cr}_{2} \mathrm{O}_{7}$ and $\mathrm{K}_{2} \mathrm{CrO}_{4}$ in which $\mathrm{Cr}$ is present in $3^{+}$and $6^{+}$oxidation states. The study has been carried out by measuring the $\mathrm{K} \mathrm{X}$-ray absorption edges of $\mathrm{Mn}$ and $\mathrm{Cr}$ in the above compounds in a dispersive X-ray absorption spectroscopy beamline at INDUS-2 Synchrotron Radiation Source. It should be noted that most of the earlier studies on chemical shifts of X-ray absorption edges, particularly on Mn and Cr compounds (Ghatikar et al 1977; Padalia and Nayak 1977; Manthiram et al 1980; Mande and Apte 1981) reported in the literature, are based on the data obtained by laboratory EXAFS measurements using weak conventional X-ray sources and hence may lack reliability.

\section{Experimental}

Samples of appropriate weight, estimated to obtain a reasonable edge jump were collected in powder form and mixed thoroughly with cellulose powder to obtain total weight of $100 \mathrm{mg}$, and homogenous pellets of $15 \mathrm{~mm}$ diameter were prepared using an electrically operated hydraulic press. X-ray absorption spectroscopy measurements near the absorption edges (viz. XANES measurements) were carried out at the dispersive EXAFS beamline (BL-8) in transmission mode at the INDUS-2 Synchrotron Source $(2.0 \mathrm{GeV}$, $100 \mathrm{~mA}$ ) at Raja Ramanna Centre for Advanced Technology (RRCAT), Indore, India (Bhattacharyya et al 2009; Gaur et al 2011; Basu et al 2012a, b). The beamline used a 
460-mm long $\mathrm{Si}(111)$ crystal having $2 d$ value equal to 6.2709 A mounted on an elliptical bender, which could bend the crystal to take the shape of an ellipse such that the synchrotron source and the sample position were at the two foci of the ellipse. The crystal was first set in such a fashion that the central portion makes the proper Bragg angle $\left(\theta_{0}\right)$ w.r.t. the incident beam and it selected the energy $\left(E_{0}\right)$ corresponding to the absorption edge of interest. Due to the divergent nature of the synchrotron beam, the angle of incidence varied from $\left(\theta_{0}-\Delta \theta\right)$ at one end of the crystal to $\left(\theta_{0}+\Delta \theta\right)$ at the other end and hence a band of energy of $E_{0} \pm \Delta E$ was selected by the crystal and the whole band simultaneously fell on the sample due to the elliptical bending of the crystal. The elliptical optics offered minimum aberration. Radiation transmitted through the sample got defocused, spatially dispersed and was subsequently detected by a positionsensitive CCD detector having $2048 \times 2048$ pixels. The plot of absorption vs photon energy was obtained by recording the intensities $I_{0}$ and $I_{\mathrm{T}}$, as the CCD outputs, without and with the sample, respectively and the absorption coefficient, $\mu$, was obtained using the relation:

$$
I_{\mathrm{T}}=I_{0} e^{-\mu x},
$$

where $x$ is the thickness of the absorber. Thus, using the above beamline, the full EXAFS spectrum of the sample at any specified absorption edge can be obtained as a single shot within a time frame of $300 \mathrm{~ms}$.

For the present measurements, the $\mathrm{Si}$ (111) crystal was set at a proper Bragg angle to obtain a band of energy around $6539 \mathrm{eV}$ for the XANES measurement at Mn edge (around $5989 \mathrm{eV}$ for Cr K-edge XANES measurements). L3 absorption edge of Sm using a pellet of commercially available powder of $\mathrm{Sm}_{2} \mathrm{O}_{3}$ and $\mathrm{K}$ absorption edge of Mn using standard foil of Mn were measured under the same setting of goniometer and crystal bender to calibrate the CCD channels for XANES measurements of Mn compounds. Calibration of CCD channels in case of $\mathrm{Cr}$ compounds was done by measuring $\mathrm{L} 3$ absorption edges of $\mathrm{Pr}$ and $\mathrm{Nd}$ using pellets of commercially available $\mathrm{Pr}_{2} \mathrm{O}_{3}$ and $\mathrm{Nd}_{2} \mathrm{O}_{3}$ powders.

It should be noted here that the present measurements were carried out with synchrotron radiation as source unlike the other results reported in the reference list where much weaker laboratory sources were used. For each sample, at least 200 spectra were recorded and average was taken to have better accuracy in the data. This has been possible due to the high flux of synchrotron radiation and very fast read out time of the CCD (300 ms) detector used in the present measurement. It should also be mentioned here that, generally in the normal operation of the beamline, an energy resolution of $\sim 1 \mathrm{eV}$ at $9 \mathrm{keV}\left(E / \Delta E \sim 10^{4}\right)$ was achieved, when a spatially dispersed band of $1 \mathrm{keV}$ fell on the 2000 pixels of CCD detector. However, in case of the present measurements, since we are only concerned with the XANES part (portion close to the absorption edge), the goniometer was positioned in such a way that a smaller band of $150 \mathrm{eV}$ fell on CCD spreading over its 2000 pixels and hence a much better energy resolution was obtained $(\sim 0 \cdot 1 \mathrm{eV})$.

\section{Results and discussion}

Figure 1 shows experimental XANES spectra ( $\mu$ vs energy plots) at Mn K-edge in different Mn samples viz. Mn metal, $\mathrm{MnCl}_{2}, \mathrm{MnCO}_{3}, \mathrm{MnSO}_{4} \cdot \mathrm{H}_{2} \mathrm{O}, \mathrm{Mn}_{2} \mathrm{O}_{3}, \mathrm{CaMnO}_{3}$ and $\mathrm{MnO}_{2}$. It can be seen from figure 1 that for almost all the $\mathrm{Mn}$ compounds, one strong pre-edge peak is observed in their respective absorption spectrum, because of transition corresponding to metal $1 s$ orbital to metal oxide $d-p$ hybridized orbital. This feature is a characteristic of tetrahedral and/or distorted octahedral coordination (Apte and Mande 1981) of the metal cation, while a lack of pre-dge bump in $\mathrm{MnCl}_{2}$ is possibly because of a perfect octahedral coordination (Nietubyc et al 2001). The K edge positions in different samples are obtained by finding out the 1 st peak in the 1 st derivative of the $\mu$ vs energy plot near the edge. The chemical shift values $(\Delta E)$ for all the samples are listed in table 1 . There are wide variations in the edge shift in Mn compounds measured by different researchers (Ghatikar et al 1977; Mande and Apte 1981; Basu et al 2012a, b) and our result being closer to that of Ghatikar et al (1977).

Figure 2 shows K-edge XANES spectra ( $\mu$ vs energy plots) for $\mathrm{Cr}$ compounds $\left(\mathrm{CrCl}_{3} \cdot 6 \mathrm{H}_{2} \mathrm{O}, \mathrm{Cr}_{2} \mathrm{O}_{3}, \mathrm{Cr}\left(\mathrm{SO}_{4}\right)_{3}\right.$, $\mathrm{Cr}_{2}\left(\mathrm{NO}_{3}\right)_{3} \cdot 3 \mathrm{H}_{2} \mathrm{O}, \mathrm{K}_{2} \mathrm{Cr}_{2} \mathrm{O}_{7}$ and $\left.\mathrm{K}_{2} \mathrm{CrO}_{4}\right)$. In this case also, for compounds like $\mathrm{K}_{2} \mathrm{Cr}_{2} \mathrm{O}_{7}$ and $\mathrm{K}_{2} \mathrm{CrO}_{4}$, where $\mathrm{Cr}$ is present in $\mathrm{Cr}^{6+}$ oxidation state and having tetrahedral coordination, large pre-edge feature appears in their respective absorption spectrum at $5996.5 \mathrm{eV}$, which is a characteristic of $1 s$ to $3 d$ orbital transition (Peterson et al 1997; Huggins et al 1999; Najih and Huffman 1999; Shaffer et al 2001; Dokken et al 2007; Parson et al 2007). However, the pre-edge

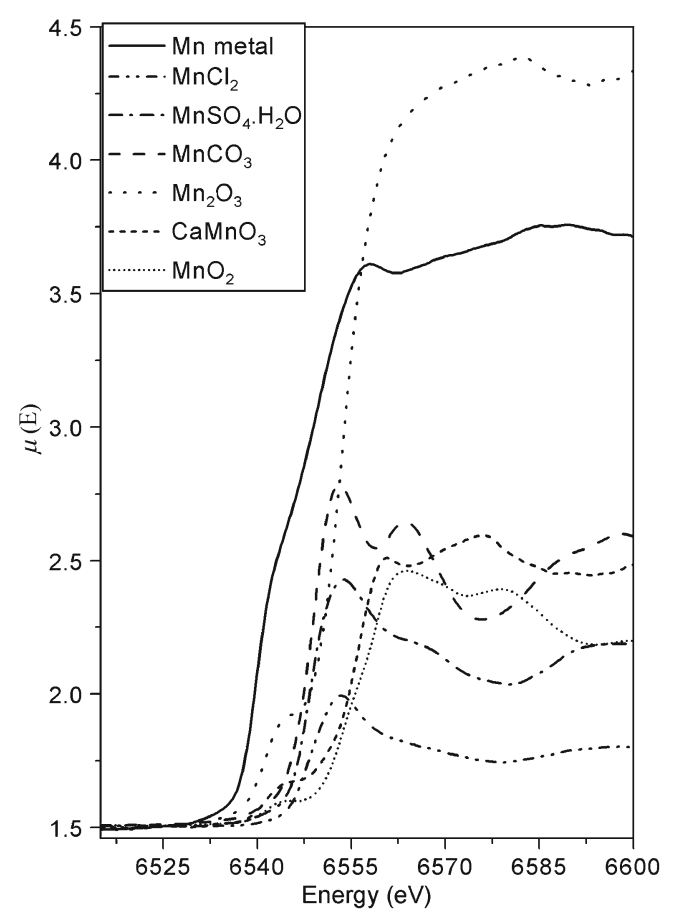

Figure 1. XANES spectra of different Mn compounds around Mn K edge. 
Table 1. Chemical shift of Manganese $\mathrm{K}$ edge and the estimated effective charge on the manganese ion in the compounds.

\begin{tabular}{|c|c|c|c|c|}
\hline \multirow[b]{2}{*}{ Compound } & \multirow{2}{*}{$\begin{array}{c}\text { Mn ion } \\
\text { oxidation state }\end{array}$} & \multirow{2}{*}{$\begin{array}{c}\text { Chemical shift } \\
(\Delta E)(\mathrm{eV})\end{array}$} & \multicolumn{2}{|c|}{ Effective charge $(q)$} \\
\hline & & & Suchet's formula & Pauling's formula \\
\hline $\mathrm{MnCl}_{2}$ & $2+$ & $8 \cdot 17 \pm 0 \cdot 1$ & $1 \cdot 18$ & 1.66 \\
\hline $\mathrm{MnSO}_{4} \cdot \mathrm{H}_{2} \mathrm{O}^{*}$ & $2+$ & $8 \cdot 40 \pm 0 \cdot 1$ & $1 \cdot 22$ & 1.69 \\
\hline $\mathrm{MnCO}_{3}^{*}$ & $2+$ & $9 \cdot 30 \pm 0 \cdot 1$ & $1 \cdot 35$ & $1 \cdot 83$ \\
\hline $\mathrm{Mn}_{2} \mathrm{O}_{3}$ & $3+$ & $13 \cdot 62 \pm 0 \cdot 1$ & $1 \cdot 87$ & $2 \cdot 38$ \\
\hline $\mathrm{MnO}_{2}$ & $4+$ & $18 \cdot 83 \pm 0 \cdot 1$ & $2 \cdot 37$ & $2 \cdot 92$ \\
\hline $\mathrm{CaMnO}_{3}$ & $4+$ & $16 \cdot 33 \pm 0 \cdot 1$ & 1.49 & $\begin{array}{l}\text { od } 1 \\
\text { od } 2\end{array}$ \\
\hline $\mathrm{CaMnO}_{3}^{*}$ & $4+$ & $16 \cdot 33 \pm 0 \cdot 1$ & $\begin{array}{l}2 \cdot 37 \\
2 \cdot 15\end{array}$ & $\begin{array}{l}2 \cdot 92 \\
2 \cdot 67\end{array}$ \\
\hline
\end{tabular}

*Effective charge calculated from the calibration curve of $\Delta E$ vs $q$.

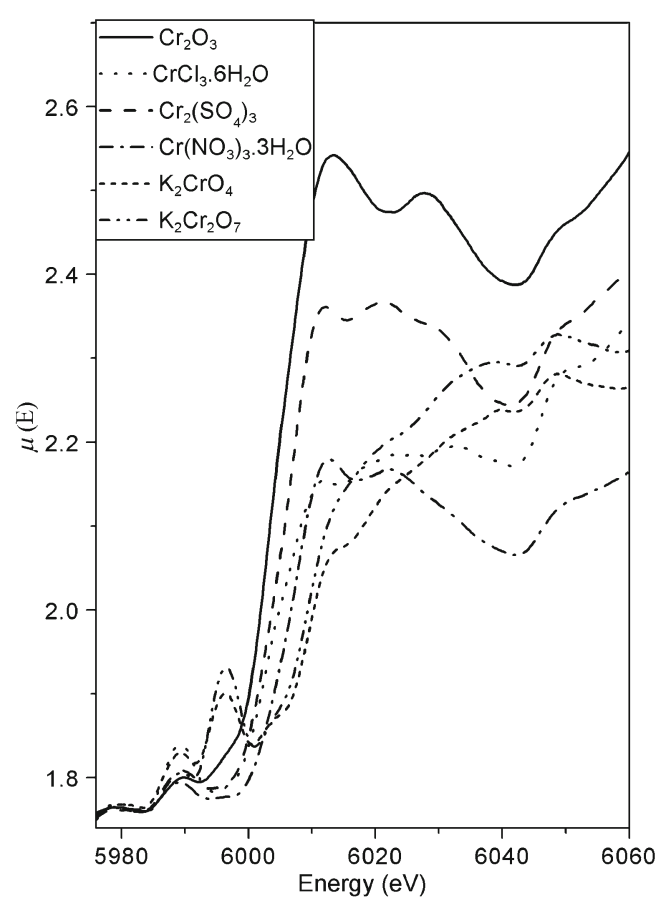

Figure 2. XANES spectra of different $\mathrm{Cr}$ compounds around $\mathrm{Cr} \mathrm{K}$ edge.

features are very weak for the compounds where $\mathrm{Cr}$ is present in $\mathrm{Cr}^{3+}$ oxidation state and having octahedral coordination, viz. in $\mathrm{CrCl}_{3} \cdot 6 \mathrm{H}_{2} \mathrm{O}, \mathrm{Cr}_{2} \mathrm{O}_{3}, \mathrm{Cr}\left(\mathrm{SO}_{4}\right)_{3}$ and $\mathrm{Cr}_{2}\left(\mathrm{NO}_{3}\right)_{3} \cdot 3 \mathrm{H}_{2} \mathrm{O}$, since $1 s$ to $3 d$ transition is forbidden in octahedral compounds. Edge shifts for all the compounds are calculated at the maximum of first derivative of edge. Chemical shift values for all the $\mathrm{Cr}$ compounds are shown in table 2. Edge shifts obtained in some Cr compounds agree well with the result obtained by Manthiram et al (1980).

As discussed in the 'Introduction' section, chemical environment around the central absorbing atom such as electronegativity of anions, coordination numbers, oxidation state etc determine the shift in absorption edges of the atom.
Various studies (Nigam and Gupta 1974; Kondawar and Mande 1976; Ballal and Mande 1977; Apte and Mande 1981; Chetal et al 1988; Pandey et al 1990; Hinge et al 2011; Joseph et al 2012) have shown that this combined effect of chemical environment can be quantitatively presented by the quantity 'effective charge' $(q)$. Formation of chemical bond in a compound involves redistribution of valence electrons of the constituent atoms and effective charge is a hypothetical parameter which gives a measure of the charge residing over the cation when it forms a bond with a ligand. Apart from the valency, it takes care of the electronegativity of the pair of atoms forming the bond, covalent nature of the bond, coordination number etc and thus quantitatively takes care of the chemical environment around the absorbing metal ions.

Several empirical relations have been proposed in the literature to estimate the effective charge on a metal cation in a compound. According to Suchet (1965), the effective charge on a cationic species involved in formation of a chemical bond can empirically be represented by

$$
q=n\left[1-0.01185\left(\frac{Z}{r^{\prime}}+\frac{Z^{\prime}}{r}\right)\right],
$$

where $Z, r$ and $n$ are, respectively the total number of electrons, ionic radius and oxidation number of the cation; and the primed symbols refer to the anion in the compounds. Using the above formula, the effective charge on $\mathrm{Mn}$ in $\mathrm{MnCl}_{2}, \mathrm{Mn}_{2} \mathrm{O}_{3}$ and $\mathrm{MnO}_{2}$ are calculated and are given in table 1. Similarly, effective charges on $\mathrm{Cr}$ in $\mathrm{CrCl}_{3} \cdot 6 \mathrm{H}_{2} \mathrm{O}$ and $\mathrm{Cr}_{2} \mathrm{O}_{3}$ are calculated using the above method and are given in table 2. It has been observed by other researchers also that the Suchet's formula, given here is not suitable for calculating $q$ when anion radicals, e.g., $\mathrm{CO}_{3}^{2-}, \mathrm{SO}_{4}^{2-}, \mathrm{NO}_{3}^{-}$, etc are present as ligands to metal ion (Hinge et al 2011; Joseph et al 2012).

The Pauling's method to estimate effective charge on the other hand, is represented by the following relation (Pauling 1960):

$$
q=n I,
$$


Table 2. Chemical shift of Chromium K edge and the estimated effective charge on the chromium ions in the compounds.

\begin{tabular}{|c|c|c|c|c|}
\hline \multirow[b]{2}{*}{ Compound } & \multirow{2}{*}{$\begin{array}{c}\text { Cr ion } \\
\text { oxidation state }\end{array}$} & \multirow{2}{*}{$\begin{array}{l}\text { Chemical shift } \\
\qquad(\Delta E)(\mathrm{eV})\end{array}$} & \multicolumn{2}{|c|}{ Effective charge $(q)$} \\
\hline & & & Suchet's formula & Pauling's formula \\
\hline $\mathrm{CrCl}_{3} \cdot 6 \mathrm{H}_{2} \mathrm{O}$ & $3+$ & $13 \cdot 73 \pm 0 \cdot 1$ & 1.55 & $2 \cdot 25$ \\
\hline $\mathrm{Cr}_{2} \mathrm{O}_{3}$ & $3+$ & $14 \cdot 27 \pm 0 \cdot 1$ & $1 \cdot 87$ & $2 \cdot 31$ \\
\hline $\mathrm{Cr}_{2}\left(\mathrm{SO}_{4}\right)_{3}^{*}$ & $3+$ & $14 \cdot 27 \pm 0 \cdot 1$ & 1.87 & \\
\hline $\mathrm{Cr}\left(\mathrm{NO}_{3}\right)_{3} \cdot 3 \mathrm{H}_{2} \mathrm{O}^{*}$ & $3+$ & $15 \cdot 69 \pm 0.1$ & $2 \cdot 02$ & \\
\hline \multirow[t]{5}{*}{$\mathrm{K}_{2} \mathrm{CrO}_{4}$} & $6+$ & $20 \cdot 51 \pm 0 \cdot 1$ & \multirow{2}{*}{\multicolumn{2}{|c|}{ Method 1}} \\
\hline & & & & \\
\hline & & & $1 \cdot 01$ & 1.04 \\
\hline & & & \multicolumn{2}{|c|}{ Method 2} \\
\hline & & & $2 \cdot 31$ & 1.92 \\
\hline $\mathrm{K}_{2} \mathrm{Cr}_{2} \mathrm{O}_{7}^{*}$ & $6+$ & $20 \cdot 34 \pm 0 \cdot 1$ & $2 \cdot 31$ & \\
\hline
\end{tabular}

*Effective charge calculated from the calibration curve of $\Delta E$ vs $q$.

where $n$ is the valence of the absorbing cation and $I$ the ionicity of the metal-ligand bond calculated as below:

$$
I=1-\frac{n}{c} \exp \left[-\left(X_{1}-X_{\mathrm{a}}\right)^{2} / 4\right]
$$

where $X_{1}$ and $X_{\mathrm{a}}$ are the electronegativities of the ligand and the absorbing atom, respectively and $c$ the coordination number of the absorbing atom. The above expression for ionicity of a partially covalent bond is found to agree with experimentally observed electric dipole moment of many standard molecules. Effective charges on $\mathrm{Mn}$ and $\mathrm{Cr}$ in the respective binary compounds (without radical as ligands) are also calculated using the Pauling's formula and are shown in tables 1 and 2, respectively.

It should be mentioned here that for finding the effective charges in ternary compounds, viz. $\mathrm{CaMnO}_{3}, \mathrm{~K}_{2} \mathrm{CrO}_{4}$ and $\mathrm{K}_{2} \mathrm{Cr}_{2} \mathrm{O}_{7}$, no separate formula was suggested by Suchet (1965). However, Ghatikar et al (1977) suggested a methodology for finding the effective charge on one of the cations in a ternary compound where effective charges on the cations of the constituent binary compounds (viz. $\mathrm{CaO}$ and $\mathrm{Mn}_{2} \mathrm{O}_{3}$, in case of $\mathrm{CaMnO}_{3}$ ) are determined first and the average effective positive charge is distributed on the two cations in the reverse ratio of their electronegativities. Effective charge on $\mathrm{Mn}$ in $\mathrm{CaMnO}_{3}$ was found by the above method (hereafter, referred to as method 1), where the effective charges of the cations in the constituent binaries viz. $\mathrm{Mn}_{2} \mathrm{O}_{3}$ and $\mathrm{CaO}$, are obtained by both Suchet and Pauling methods and the values are shown in table 1. However, as seen in table 1, effective charges on $\mathrm{Mn}$ in $\mathrm{CaMnO}_{3}$, obtained using method 1, was much less than expected in both the cases for a compound having $\mathrm{Mn}$ in $\mathrm{Mn}^{4+}$ oxidation state and for a chemical shift $(\Delta E)$ value of $16.33 \mathrm{eV}$. The other method (method 2) to find out effective charge on a cation in a ternary compound, also followed by other workers (Chetal et al 1988; Pandey et al 1990) consider only the 1st coordination shell of the particular cation in the ternary compound. Since in $\mathrm{CaMnO}_{3}$, $\mathrm{Mn}$ has a $\mathrm{Mn}^{4+}$ oxidation state and an octahedral oxygen coordination as in $\mathrm{MnO}_{2}$, effective charge on $\mathrm{Mn}$ in $\mathrm{CaMnO}_{3}$, according to method 2 would be same as that on $\mathrm{Mn}$ in $\mathrm{MnO}_{2}$ and are given in table 1. This value is more realistic than that obtained by method 1 , however, since the chemical shift in $\mathrm{CaMnO}_{3}$ is lower than that found in $\mathrm{MnO}_{2}$, it appears that method 2 also fails to predict the correct effective charge of $\mathrm{Mn}$ in $\mathrm{CaMnO}_{3}$. Hence, we have opted not to include the effective charge on $\mathrm{Mn}$ in $\mathrm{CaMnO}_{3}$ in generating the calibration curve for $\Delta E$ vs $V$, as discussed below and have obtained the effective charge value from the calibration curve itself.

For finding out effective charge on $\mathrm{Cr}$ in $\mathrm{K}_{2} \mathrm{CrO}_{4}$ by method 1, similarly, we have found out effective charge on $\mathrm{K}$ in $\mathrm{K}_{2} \mathrm{O}$ and $\mathrm{Cr}$ in $\mathrm{CrO}_{3}$ by both Suchet and Pauling methods and subsequently, the averaging has been carried out as discussed above to find out the effective charge on $\mathrm{Cr}$ in $\mathrm{K}_{2} \mathrm{CrO}_{4}$. However, as seen in table 2, the discussed method has yielded very low value of effective charge on $\mathrm{Cr}^{6+}$ in $\mathrm{K}_{2} \mathrm{CrO}_{4}$ and hence cannot be accepted. However, if we consider the 1st coordination shell method (method 2), i.e. tetrahedral coordination of oxygen around $\mathrm{Cr}$ as in $\mathrm{CrO}_{3}$ (Pantelouris et al 2004), the effective charge of $\mathrm{Cr}$ in $\mathrm{K}_{2} \mathrm{CrO}_{4}$ appears to be reasonable for $\mathrm{Cr}^{6+}$ oxidation state, using the Suchet's formula, as shown in table 2. Hence, the above effective charge values on $\mathrm{Cr}$ in $\mathrm{K}_{2} \mathrm{CrO}_{4}$ are taken into account in generating the calibration curve of $q$ vs $\Delta E$ in case of $\mathrm{Cr}$ compounds as discussed below. However, effective charge on $\mathrm{Cr}$ in $\mathrm{K}_{2} \mathrm{CrO}_{4}$ as obtained using Pauling's formula is still not found to be reasonable even by method 2 , as seen in table 2 and hence the calibration curve has not been drawn for Cr compounds using Pauling's formula.

Figures 3 and 4 show plots of measured chemical shift, $\Delta E$, as a function of the calculated effective charge $(q)$ for $\mathrm{Mn}$ and $\mathrm{Cr}$ compounds. For $\mathrm{Mn}$ compounds, effective charges obtained by both Suchet's and Pauling formulae have been plotted in figure $3(a$ and $b$ ), while for $\mathrm{Cr}$ compounds, only effective charge obtained from Suchet's formula has been used since Pauling formula possibly yielded wrong result for $\mathrm{K}_{2} \mathrm{Cr}_{2} \mathrm{O}_{7}$ and $\mathrm{K}_{2} \mathrm{CrO}_{4}$ samples. 


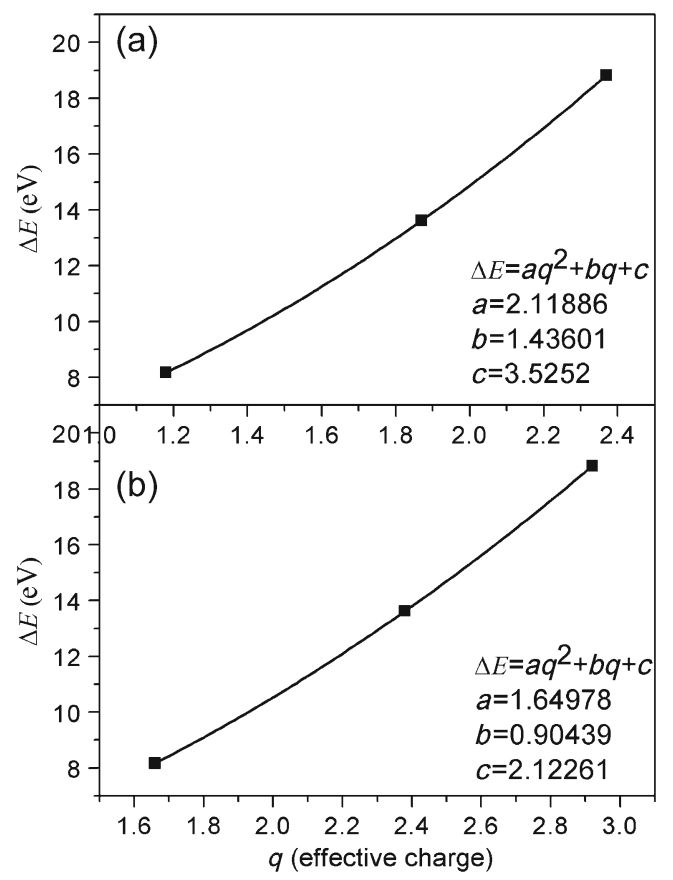

Figure 3. $\Delta E$ vs $q$ for Mn compounds with polynomial fit where effective charge is calculated using (a) Suchet's formula and (b) Pauling's formula.

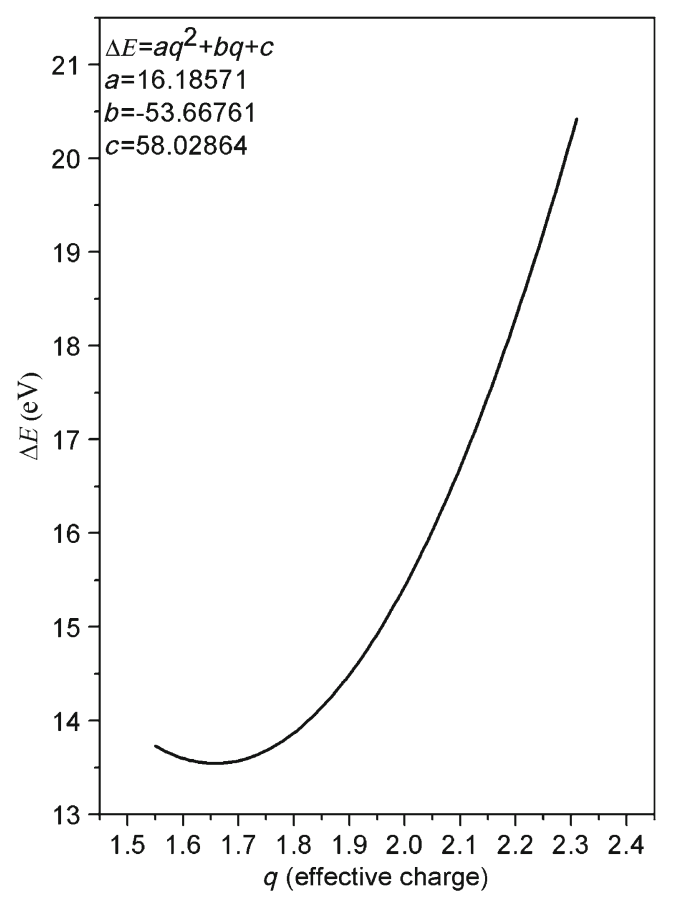

Figure 4. $\Delta E$ vs $q$ for $\mathrm{Cr}$ compounds with polynomial fit where effective charge is calculated using Suchet's formula.

It has been observed that for both $\mathrm{Mn}$ and $\mathrm{Cr}$ compounds, the variation of chemical shifts as a function of effective charge can be described by a quadratic equation as follows:

$$
\Delta E=a q+b q^{2}+c .
$$

The best fit values of the parameters $a, b$ and $c$ are given in the corresponding curves. Similar quadratic variation of chemical shift as a function of effective charge has been reported by other researchers also (Kondawar and Mande 1976; Apte and Mande 1981; Chetal et al 1988; Pandey et al 1990; Hinge et al 2011; Joseph et al 2012) for compounds of various metal ions. Subsequently, using the above calibration curves and the measured chemical shifts, we have estimated effective charges on metal ions in compounds having radicals viz. $\mathrm{Mn}$ ion in $\mathrm{MnCO}_{3}, \mathrm{MnSO}_{4} \cdot \mathrm{H}_{2} \mathrm{O}$ and $\mathrm{CaMnO}_{3}$ and on $\mathrm{Cr}$ ion in $\mathrm{Cr}\left(\mathrm{SO}_{4}\right)_{3}, \mathrm{Cr}_{2}\left(\mathrm{NO}_{3}\right)_{3} \cdot 3 \mathrm{H}_{2} \mathrm{O}$ and $\mathrm{K}_{2} \mathrm{Cr}_{2} \mathrm{O}_{7}$ and the values are listed in tables 1 and 2 . The estimated effective charges agree well with that reported by Mande and Apte (1981) for Mn compounds and by Manthiram et al (1980) for $\mathrm{Cr}$ compounds. As seen in table 2, for $\mathrm{Cr}$ compounds, the chemical shift $(\Delta E)$ and effective charge $(q)$ have been found to be higher for $\mathrm{NO}_{3}$ ligand compared to $\mathrm{SO}_{4}$ ligand for the same oxidation state of $\mathrm{Cr}$, i.e. $\mathrm{Cr}^{3+}$. This agrees with the result obtained by Hinge et al (2011) for $\mathrm{Cu}$ compounds and is indicative of more ionic nature of the metal$\mathrm{NO}_{3}$ bonds compared to metal- $\mathrm{SO}_{4}$ bonds. Similarly, from table 1 , it can be seen that the chemical shift $(\Delta E)$ and effective charge $(q)$ have been found to be higher for $\mathrm{CO}_{3}$ ligand compared to $\mathrm{SO}_{4}$ ligand for the same oxidation state of $\mathrm{Mn}$, i.e. $\mathrm{Mn}^{2+}$, establishing covalent character of the $\mathrm{SO}_{4}$ ligand.

\section{Conclusions}

X-ray absorption spectroscopy measurements were carried out at the Mn K edge around $6539 \mathrm{eV}$ on elemental Mn foil and few $\mathrm{Mn}$ compounds viz. $\mathrm{MnCl}_{2}, \mathrm{MnCO}_{3}, \mathrm{MnSO}_{4} \cdot \mathrm{H}_{2} \mathrm{O}$, $\mathrm{Mn}_{2} \mathrm{O}_{3}, \mathrm{CaMnO}_{3}$ and $\mathrm{MnO}_{2}$, where $\mathrm{Mn}$ is present in $2^{+}$, $3^{+}$and $4^{+}$oxidation states and with tetrahedral or octahedral coordinations. Similarly, measurements at the $\mathrm{Cr}$ $\mathrm{K}$ edge were carried out on $\mathrm{Cr}$ foil and on a few $\mathrm{Cr}$ containing compounds viz. $\mathrm{CrCl}_{3} \cdot 6 \mathrm{H}_{2} \mathrm{O}, \mathrm{Cr}_{2} \mathrm{O}_{3}, \mathrm{Cr}\left(\mathrm{SO}_{4}\right)_{3}$, $\mathrm{Cr}_{2}\left(\mathrm{NO}_{3}\right)_{3} \cdot 3 \mathrm{H}_{2} \mathrm{O}, \mathrm{K}_{2} \mathrm{Cr}_{2} \mathrm{O}_{7}$ and $\mathrm{K}_{2} \mathrm{CrO}_{4}$. Measurements were carried out using the energy dispersive EXAFS beamline at INDUS-2 Synchrotron radiation source at RRCAT, Indore. Energy shifts of $\sim 8-16 \mathrm{eV}$ were observed for $\mathrm{Mn}$ $\mathrm{K} X$-ray absorption edge in the Mn-compounds while shifts of 13-20 eV were observed for $\mathrm{Cr} \mathrm{K}$ edge in $\mathrm{Cr}$ compounds compared to their values in elemental $\mathrm{Mn}$ and $\mathrm{Cr}$, respectively. The different chemical shifts observed for the compounds having the same oxidation state of the cation but different anions or ligands show the effect of different chemical environments surrounding the cations. The above chemical effect has been quantitatively described by determining the effective charges on $\mathrm{Mn}$ and $\mathrm{Cr}$ cations in the above compounds. Effective charges were determined analytically using two standard available formulae for compounds having simple anionic ligands and the calibration curves for the chemical shift vs effective charge were generated for both $\mathrm{Mn}$ and $\mathrm{Cr}$ containing compounds. Using the above calibration curves, effective charges on the cations in compounds having radicals as ligands have been determined. 


\section{Acknowledgement}

The authors wish to acknowledge Dr NK Sahoo, Applied Spectroscopy Division and Dr A Chatterjee, Nuclear Physics Division, Bhabha Atomic Research Centre, Mumbai, for their keen interest during this work.

\section{References}

Apte M Y and Mande C 1981 J. Phys. Chem. Sol. 42605

Ballal M M and Mande C 1977 J. Phys. Chem. Sol. 381383

Basu S, Naidu B S, Pandey M, Sudarsan V, Jha S N, Bhattacharyya D, Vatsa R K and Kshirsagar R J 2012a Chem. Phys. Lett. 52825

Basu S, Varma Salil, Shirsat A N, Wani B N, Bharadwaj S R, Chakrabarti A, Jha S N and Bhattacharyya D 2012b J. Appl. Phys. 111053532

Bhattacharyya D, Poswal A K, Jha S N, Sangeeta and Sabharwal S C 2009 Nucl. Instrum. Meth. Phys. Res. A609 286

Chetal A R, Mahto P and Sarode P R 1988 J. Phys. Chem. Sol. 49 279

Gaur A, Shrivastava B D, Gaur D C, Prasad J, Srivastava K, Jha S N, Bhattacharyya D, Poswal A K and Deb S K 2011 J. Coord. Chem. 641265

Ghatikar M N, Padalia B D and Nayak R M 1977 J. Phys. C: Solid State Phys. 104173
Hinge H K, Joshi S K, Shrivastava B D, Prasad J and Srivastava K 2011 Indian J. Pure Appl. Phys. 49168

Huggins F E, Najih M and Huffman G P 1999 Fuel 78233

Joseph D, Basu S, Jha S N and Bhattacharyya D 2012 Nucl. Inst. Meth. Phys. Res. B274 126

Kondawar V K and Mande C 1976 J. Phys. C: Solid State Phys. 91351

Mande C and Apte M Y 1981 Bull. Mater. Sci. 3193

Manthiram A, Sarode P R, Madhusudan W H, Gopalakrishana J and Rao C N 1980 J. Phys. Chem. 842200

Nietubyc R, Sobczak E and Attenkofer K E 2001 J. Alloys Compd. 328126

Nigam A K and Gupta M K 1974 J. Phys. F: Metal. Phys. 41084

Pantelouris A, Modrow H, Pantelouris M, Hormes J and Reinen D 2004 Chem. Phys. 30013

Pandey S K, Chetal A R and Sarode P R 1990 J. Phys. Soc. Jap. 591848

Parson J G, Dokken K, Peralta-Videa J R, Romero-Gonzalez J and Gardea-Torresdey J L 2007 Appl. Spectrosc. 61338

Pauling L 1960 The nature of chemical bond (New York: Cornell Univ. Press)

Peterson M L, Brown G E Jr, Parks G A and Stain C L 1997 Geochim. Cosmochim. Acta 613399

Shaffer R E, Cross J O, Rose-Pehrsson S L and Elam W T 2001 Anal. Chim. Acta 442295

Suchet J P 1965 Chemical physics of semiconductors (London: Van Nostrand) 